\begin{tabular}{|l|l|l||}
\hline \multicolumn{2}{|c|}{ PublisherInfo } \\
\hline \hline PublisherName & $:$ & BioMed Central \\
\hline \hline PublisherLocation & $:$ & London \\
\hline \hline PublisherImprintName & $:$ & BioMed Central \\
\hline \hline
\end{tabular}

\title{
Racial differences in breast carcinoma
}

\begin{tabular}{|l|l|l||}
\hline \multicolumn{2}{|c||}{ ArticleInfo } \\
\hline \hline ArticleID & $:$ & 3687 \\
\hline \hline ArticleDOI & $:$ & $10.1186 /$ bcr-2000-66650 \\
\hline \hline ArticleCitationID & $:$ & 66650 \\
\hline \hline ArticleSequenceNumber & $:$ & 53 \\
\hline \hline ArticleCategory & $:$ & Paper Report \\
\hline ArticleFirstPage & $:$ & 1 \\
\hline \hline ArticleLastPage & $:$ & 4 \\
\hline \hline & & RegistrationDate : 2000-1-26 \\
ArticleHistory & $:$ & OnlineDate \\
\hline \hline ArticleCopyright & $:$ & Current Science Ltd2000-1-26 \\
\hline \hline ArticleGrants & $:$ & \\
\hline \hline ArticleContext & $:$ & 1305822 \\
\hline \hline
\end{tabular}




\section{Keywords}

Age, histology, hormone receptors, race, stage, surveillance, survival

\section{Introduction}

Breast cancer is common in women and although its incidence is increasing, mortality rates for breast carcinoma are beginning to show a significant decrease. However serious gaps remain in mortality rates between racial groups. African American women have a lower-age adjusted incidence rate for breast carcinoma compared with Caucasian women, but suffer a poorer age-adjusted breast carcinoma mortality rate. Previous studies have provided inconsistent results regarding the independent effects of race on breast cancer survival.

\section{Aims}

To examine the effects of race on the survival of patients with breast carcinoma.

\section{Comments}

This is a large population based study that confirms the importance of race in the development and prognosis of breast cancer. This study also confirms that distinct biological differences occur in tumors from American African women when compared to those from Caucasian women . The former are more likely to have steroid receptor negative and high grade tumors such as medullary carcinoma. The latter are more likely to have steroid receptor positive tumors and low grade tumous such as lobular carcinoma or tubular carcinoma. These differences may play an important role in deciding on preventative measures for breast cancer, particularly if anti-estrogen drug therapy is considered.

\section{Methods}


The data was collected and provided by the National Cancer Institutes Surveillance, Epidemiology, and End Results (SEER) Program. The information was from all cases of invasive cancer diagnosed in nine geographic areas of the United States and represented approximately $12 \%$ of the US population. The study included 135,424 women that were diagnosed with primary breast cancer between 1988 to 1995. The variables analysed included tumor stage (using the TNM classification system), race, patient age, menopausal status, estrogen and progesterone status and histologic category. Race was categorised as African American or Caucasian, all other races were not analysed due to the small numbers in each group when multivariate analysis was performed. The data was analysed using the $t$ test, frequency tables, chi-square statistic, log-rank statistics, and Cox proportional hazards multiple regression analyses.

\section{Results}

The African American women were, when compared with Caucasian women, diagnosed with breast cancer at a younger age $(57.8$ years versus 62.6 years, $P<0.0001)$ and were more likely to be premenopausal ( $<50$ years). They were also more likely to present at a later stage of disease, have tumors negative for steroid receptors, and were more likely to have high grade lesions like inflammatory, medullary or papillary carcinomas. Furthermore, survival from all cancer deaths was significantly worse for African American women when compared with Caucasian women $(P<0.0001)$. This was also true for all stage categories, except for in situ disease. The risk of death for women with stage 1 breast carcinomas was 1.54 times greater for African American women compared with Caucasian women. In addition, race was a significant independent risk factor for mortality $(67 \%$ higher in African American women).

\section{Discussion}

The findings of this study support previous research showing that African American women that are diagnosed with breast carcinoma have a significantly increased risk of death from cancer when compared with Caucasian women. The finding that race is an independent risk factor may be linked to a number of variables including cultural and socio-economic factors, diet and body mass index, treatment differences and differences in biological behaviour of the carcinomas that develop. Further research into the etiology of racial differences and their effect on the survival of patients with breast carcinoma is required as well as the need for public health measures designed to increase education and screening among African American women. 


\section{References}

1. Joslyn SA, West MM: Racial differences in breast carcinoma survival. Cancer . 2000, 88: 114-123. 